\title{
RECURSOS NATURAIS DE CONFORTO TÉRMICO: UM ENFOQUE URBANO
}

\author{
Isadora Mendes da Silva'; Luciana Ruggiero Gonzalez²; \\ Demóstenes Ferreira da Silva Filho ${ }^{3}$
}

(recebido em 15.06.2011 e aceito para publicação em 15.12.2011)

\section{RESUMO}

A influência positiva dos recursos naturais de conforto nas cidades tem sido demonstrada por meio de vários estudos que apontam, entre outros benefícios, a amenização da temperatura, a manutenção da umidade do ar e a redução do consumo energético. Devido à falta de planejamento urbano, má implantação da arquitetura e devastação da vegetação, as cidades tornaram-se verdadeiras ilhas de calor, desafiando constantemente seus habitantes a conviver com tamanho desconforto térmico. Dentro desse contexto este artigo objetivou realizar uma ampla revisão bibliográfica de diversos trabalhos sobre recursos naturais de conforto térmico buscando conhecer e relatar a importância da implantação da vegetação como uma estratégia eficiente na busca do conforto térmico.

Palavras chaves: Conforto térmico; Arborização urbana; Ventilação natural.

\footnotetext{
${ }^{1}$. Bióloga, Mestranda do Programa de Recursos Florestais, Departamento de Ciências Florestais, ESALQ-USP, Piracicaba, SP. E-mail: isadoramendes154@gmail.com;

2 .Bióloga, Doutoranda do Programa de Recursos Florestais, Departamento de Ciências Florestais, ESALQ-USP, Piracicaba, SP. E-mail: lucianaruggiero@usp.br

3 .Engenheiro Agrônomo, Professor do Departamento de Ciências Florestais, ESALQ-USP, Piracicaba, SP. E-mail: dfilho@usp.br.
} 


\section{NATURAL RESOURCES OF THERMAL COMFORT: AN URBAN FOCUS}

\section{ABSTRACT}

The positive influence of the natural resources of the cities' comfort has been demonstrated by several researches that indicate, among other benefits, the temperature cooling, maintaining the air moisture and reducing energy consumption. Due to the lack of urban planning, poor implementation of the architecture and devastation of vegetation, cities became true heat islands, constantly challenging their residents to live with big thermal discomfort. Within this context, this article has aimed a broad review of several papers about natural resources for thermal comfort seeking to learn and report the importance of the establishment of vegetation as an effective strategy in searching thermal comfort.

Keywords: Thermal comfort; Urban Forestry; Natural ventilation.

\section{INTRODUÇÃO}

O clima urbano é produzido pela ação do homem sobre a natureza e se relaciona à produção de condições diferenciadas de conforto / desconforto térmico, à poluição do ar, às chuvas intensas, às inundações e aos desmoronamentos das vertentes dos morros eventos de grande custo social (LOMBARDO, 1985). Condições climáticas urbanas inadequadas significam perda da qualidade de vida para uma parte da população, enquanto para outra, conduzem ao aporte de energia para o condicionamento térmico das edificações (LAMBERTS et al., 1997).

A urbanização acelerada tem comprometido a qualidade ambiental das grandes cidades, sobretudo pela perda da cobertura arbórea e a má ocupação dos solos que interferem diretamente na rugosidade do terreno, diminuindo a ventilação natural. A soma desses fatores trouxe como conseqüência o desconforto higrotérmico e formação de ilhas de calor na malha urbana.

Como a arquitetura nas cidades foi implantada sem o devido planejamento, é necessário buscar recursos de conforto na própria natureza na tentativa de solucionar ou

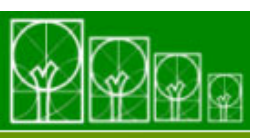

$\mathbf{S} \cdot \mathbf{B} \cdot \mathbf{A} \cdot \mathbf{U}$ Soc. Bras. de Arborização Urbana 
amenizar o desconforto nas cidades. O aumento da ventilação natural e da vegetação são recursos muito citados na literatura para obtenção do conforto devido às inúmeras funções benéficas que esses executam no meio.

A partir da análise de diversos trabalhos relacionados à arborização urbana e ventilação natural é possível notar a eficiência desses recursos naturais na mitigação do ambiente urbano gerando um microclima que proporciona uma maior condição de conforto e redução do consumo energético melhorando a qualidade ambiental das cidades.

Por meio da análise proposta neste trabalho deseja-se que os profissionais que atuam diretamente na organização e construção do espaço urbano, considerem mais ativamente os elementos que envolvem arborização e conforto térmico urbano.

\section{DESENVOLVIMENTO}

\section{Conforto Humano}

Os espaços urbanos abertos contribuiem de forma positiva para a saúde humana e o bem-estar e levam a um importante contributo para o conforto térmico humano em espaços exteriores (GEORGI; DIMITRIOU, 2010)

Segundo padrões da ASHRAE - American Society of Heating, Refrigerating and AirConditioning Engineers, Inc. (1992), conforto térmico significa: "Condição da mente que expressa satisfação com o meio térmico em que a pessoa está inserida".

A "sensação" humana de conforto térmico depende da combinação de vários fatores tanto do ambiente como do indivíduo, além de outros mais subjetivos, como idade, sexo, estado de saúde, adaptação fisiológica ao clima local ou simplesmente preferências pessoais.

A temperatura do ar, ou temperatura de bulbo seco (TBS), a temperatura radiante média (TRM), a umidade relativa e a velocidade do ar são fatores ambientais. Esses fatores estão relacionados às trocas por convecção (TBS e velocidade do ar), por radiação (TRM) e principalmente à perda de calor latente por evaporação, que depende da umidade relativa e da velocidade do ar.

Os fatores do indivíduo são: a atividade física exercida, representada pela taxa metabólica, e a resistência térmica da vestimenta utilizada. Quanto maior a atividade física, maior será o calor gerado pelo metabolismo. As atividades, tanto ativas quanto passivas,

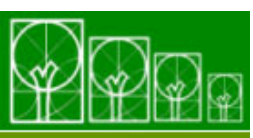

$\mathbf{S} \cdot \mathbf{B} \cdot \mathbf{A} \cdot \mathbf{U}$ Soc. Bras. de Arborização Urbana 
dos habitantes urbanos, necessitam de ambientes que sejam confortáveis termicamente (LABAKI, 2011).

$\mathrm{Na}$ área urbana, o conforto humano depende basicamente da ventilação natural e da não incidência de radiação solar direta tanto nas próprias pessoas como em materiais de construção impermeabilizantes, que absorvem o calor em vez de interceptá-los.

A incidência solar direta pode ser interceptada de maneira muito eficaz através do sombreamento proporcionado pelas árvores e o vento, que é refrigerado ao entrar em contato com as superfícies foliares e realizar trocas por convecção.

\section{Recursos Naturais de Conforto Térmico}

\section{A vegetação}

Segundo Mascaró e Mascaró (2005), a vegetação é de extrema importância para a melhoria da ambiência devido às funções que executa no meio urbano.

De acordo com Mello Filho (1985), a vegetação nas cidades absorve o gás carbônico e libera oxigênio, promovendo a melhoria da qualidade do ar urbano; sombreia, atenua a radiação e ameniza ruídos; embeleza; protege e promove a melhoria dos recursos naturais (MILANO, 1987), influencia na direção do vento (MASCARÓ, 2004) e interfere positivamente no bem estar do ser humano (salubridade mental), além de proporcionar maior conforto para o lazer e diversão (SHAMS et al., 2009).

\section{Atenuação da Radiação Solar}

\section{Sombreamento, umidade e evapotranspiração}

A radiação solar causa muitos efeitos nos centros urbanos e a vegetação é um dos elementos que pode ser utilizado para bloquear sua incidência e contribuir para o equilíbrio do balanço da energia nas cidades (PAULA, 2004).

Este efeito de atenuação da radiação solar é considerado o principal papel da vegetação urbana segundo diversos autores (FURTADO, 1994; BUENO, 2003; MASCARÓ, 2004; ABREU, 2008; SHAMS et al., 2009).

As árvores, principalmente, são instrumentos muito importantes para a transformação da radiação solar, pois transmite para o meio, de maneira difusa, as ondas

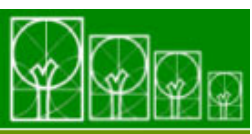

$\mathbf{S} \cdot \mathbf{B} \cdot \mathbf{A} \cdot \mathbf{U}$ Soc. Bras. de Arborização Urbana 
curtas emitidas pelo sol que incidem sobre as suas folhas justamente por refletirem parte da radiação, sendo que outra parte, ou seja, determinada faixa espectral, é absorvida e transformada em calor físico e energia química.

Oke (1978) afirma que a vegetação deve proporcionar sombra e auxiliar na diminuição da temperatura, a partir do consumo de calor latente por evaporação e pela perda de água através da transpiração.

Segundo Mascaró (2004), cada árvore responde de maneira diferente no meio que está situada, de acordo com as características inerentes de cada espécie (formato de copa, área e rugosidade foliar, coloração, e deciduidade) e do próprio meio, uma vez que o sombreamento de uma árvore é resultado da área da superfície sombreada e a interação do porte e forma da planta com a trajetória solar diária nas estações do ano (PAULA, 2004).

A evapotranspiração das plantas tem efeito muito positivo no clima urbano, pois durante este processo a planta absorve calorias, promovendo a diminuição da temperatura do microclima nas horas mais críticas.

Dimoudi; Nikolopoulou (2003) observaram que quando a temperatura do ar atinge $25^{\circ} \mathrm{C}$, a vegetação pára de contribuir com a evapotranspiração, pois seus estômatos vão se fechando à medida que a temperatura se eleva e a velocidade do vento aumenta, evitando a perda de água para o meio.

As árvores contribuem significativamente para refrigerar nossas cidades, conservar energia e podem fornecer proteção solar às casas, enquanto a evapotranspiração pode reduzir as temperaturas urbanas além de criar espaços externos agradáveis à permanência humana.

Diversos estudos relatam o aumento da umidade das áreas vegetadas em relação às não vegetadas (FONTES; DELBIN, 2002; LIMA; ROMERO, 2005; ABREU, 2008) atribuindo à vegetação a capacidade de conservar a umidade no solo, diminuindo o aquecimento por reter a irradiação.

Segundo LLANDERT (1982), a conservação da umidade pela vegetação pode ocorrer de três maneiras: evaporação física direta das chuvas, transpiração fisiológica das plantas - inversamente proporcional ao grau higrotérmico do ambiente - e a clorovaporiazação do vapor de água durante a assimilação clorofilica de CO2 atmosférico, por meio da ação dos raios solares. Este mesmo autor afirma que a evaporação em campo aberto pode ser até dez vezes maior do que embaixo da copa das árvores.

A vegetação, se inserida na área urbana de maneira correta, é capaz de combater a aridez do clima urbano pela regulação higrométrica. Entretanto, com a impermeabilização

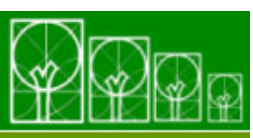

$\mathbf{S} \cdot \mathbf{B} \cdot \mathbf{A} \cdot \mathbf{U}$ Soc. Bras. de Arborização Urbana 
do solo e diminuição da cobertura arbórea, grande parte da água das chuvas deixou de ser interceptadas e/ou infiltradas, levando ao escoamento superficial parcial ou total reduzindo consideravelmente a umidade no solo em áreas urbanas.

\section{O Vento e a Ventilação Natural}

O vento é o ar em movimento, resultante do deslocamento de massas de ar, derivadas do efeito de diferença de pressão atmosféricas entre duas regiões distintas e influenciadas por efeitos locais como, por exemplo, a rugosidade do solo.

As diferenças de pressão são de origem térmica e estão diretamente relacionadas à radiação solar e processos de aquecimentos de massas de ar. Os ventos são formados a partir de influências como continentalidade, maritimidade, latitude, altitude e amplitude térmica.

A ventilação natural é o fenômeno da movimentação do ar no interior de edificações ou em ambientes externos sem a indução de nenhum sistema mecânico.

Segundo Brown e Dekay (2000), existem três princípios que definem a movimentação do ar: o resultado do atrito onde o ar se movimenta mais lentamente próximo à superfície da terra do que na atmosfera; o resultado da inércia onde o ar tende a se movimentar na mesma direção que seguia antes de encontrar um obstáculo; e o resultado da pressão, onde flui das zonas de alta para as de baixa pressão.

A modificação da rugosidade do terreno compromete a ventilação, pois cria obstáculos para a passagem de ventos ali predominantes, contribuindo para o aquecimento e promovendo a formação de novos microclimas.

Segundo Andreasi (2007), a ventilação natural é capaz de proporcionar a renovação do ar de um ambiente, provocando a dissipação de calor e a desconcentração de vapores, fumaças e poluentes (SCHIFFER; FROTA, 1999) e a velocidade do ar sobre as pessoas é fundamental para o alcance do conforto térmico.

Segundo Gratia, et al. (2004) e Andreasi (2007), a ventilação diurna proporciona uma sensação de resfriamento que auxilia na transpiração, a velocidade máxima aceitável em ambiente interno é de $0.8 \mathrm{~m} / \mathrm{s}$, o que provoca a sensação de resfriamento em torno de $3^{\circ} \mathrm{C}$. Essas sensações de resfriamento pela ventilação em velocidades de até $0,1 \mathrm{~m} / \mathrm{s}$ só podem ser sentidas em temperaturas abaixo de $18^{\circ} \mathrm{C}$, o que é indesejável. Sendo acima de $0.2 \mathrm{~m} / \mathrm{s}$, para temperaturas mais elevadas, que se pode tirar proveito da sensação de resfriamento através da velocidade do ar passando pelo corpo.

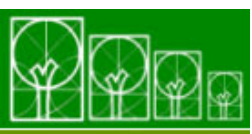

S $\cdot \mathbf{B} \cdot \mathbf{A} \cdot \mathbf{U}$ Soc. Bras. de Arborização Urbana 
Pesquisadores constataram que as correntes de ar e os efeitos climáticos dependem da estrutura da superfície da cidade e das condições do tempo (TERJUNG; LOUIE, 1974). Em estudos realizados na cidade de Salvador, Nery et al. (2006) observaram que as áreas de alta densidade ocupacional reduzem a circulação do ar e modificam a direção dos ventos dominantes. Em outro estudo realizado na Alemanha, Nobile (2003) concluiu que as áreas verdes e parques lineares servem para conduzir ar mais fresco dos arredores para os centros, contribuindo para o balanço da energia térmica nos centros das cidades.

Dimoudi e Nikolopoulou (2003) simularam a capacidade da velocidade do ar em distribuir as temperaturas das áreas verdes nas regiões mais áridas da cidade. O maior efeito é a redução da temperatura nas áreas próximas a essas áreas, mas isso depende da morfologia urbana.

Algumas pesquisas de Mascaro (2004) ressaltam a importância da vegetação no controle das correntes de ar, associadas às características de filtragem, redirecionamento ou obstrução do caminho do vento e redução da sua velocidade. Em Teresina, Lopes (2006) constatou que os espaços abertos com vegetação arbórea reduzem a velocidade dos ventos ao nível do usuário.

A utilização da vegetação como quebra-vento é destacada por Lechner (1990) em três momentos: redirecionamento do ar para as áreas superiores, criando turbulências e absorvendo a energia do ar por atrito e de acordo com a altura e densidade da copa das árvores. Boutet (1987) constatou a eficiência dos agrupamentos arbóreos na redução da velocidade do vento em mais de $50 \%$ em relação a espaços abertos.

É sabido que a eficiência na redução da velocidade dos ventos depende da disposição dos indivíduos arbóreos nos espaços abertos. Em regiões de clima quente, o efeito da redução da velocidade do vento pelas árvores não é muito desejável. Segundo Yochida et al. (2006), a falta de brisa ao nível do usuário causa desconforto. Mallick (1996) diz que a zona de conforto está intrinsecamente relacionada com a velocidade do ar. $\mathrm{O}$ fluxo de ar sobre a pele provoca a sensação de resfriamento em ambientes com temperaturas entre $30^{\circ} \mathrm{C}$ ou superiores a esse valor.

Partindo do princípio de que a vegetação funciona como um obstáculo para o fluxo de ar, foi contatado que esse efeito é somente parcial. Quando a velocidade do vento é baixa, as correntes de ar penetram pelas copas das árvores, mas quando a velocidade do ar é alta, o fluxo de ar tende a circundá-las.

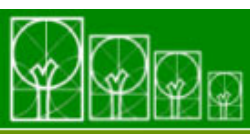

$\mathbf{S} \cdot \mathbf{B} \cdot \mathbf{A} \cdot \mathbf{U}$ Soc. Bras. de Arborização Urbana 
Para Schiffer e Frota (2003), em regiões de clima quente e úmido, como no Brasil, a ventilação natural é a estratégia mais simples para promover o conforto térmico quando a temperatura interna torna-se elevada. Jones e West (2001) consideram como um dos principais benefícios da ventilação natural a redução do consumo de energia, minimizando diretamente o uso de sistemas de ventilação mecânica e ar condicionado.

\section{Ambiência Urbana}

\section{Arborização, conforto térmico e a redução do consumo energético}

Os ambientes urbanos sempre acompanharam o cenário econômico e político. A história da humanidade demonstra que nem sempre a interferência humana na paisagem foi marcada por degradação ambiental e insalubridades, porém, atualmente com a urbanização acelerada e com a "mundialização" da economia, esses impactos ambientais adquiram uma escala global, sendo muito mais nefasto seu dano ao planeta (LEFF, 2001).

Passamos de um urbanismo "suportável e problemático" para um urbanismo "caótico, segregador e explosivo" com produtos e serviços de alta entropia. Por causa dessa situação caótica a Ambiência Urbana tem sido amplamente estudada.

O significado de Ambiência Urbana, nada mais é do que o espaço, arquitetonicamente organizado e animado, que constitui um meio físico e, ao mesmo tempo, meio estético, ou psicológico, especialmente preparado para o exercício de atividades humanas no meio urbano.

O ser humano por ser um animal homeotérmico é sensível às alterações climáticas bruscas, com grandes variações de temperatura, pois necessita manter sua temperatura corporal por volta dos $36,5^{\circ} \mathrm{C}$.

Mediante isso, trabalhos como os de Mascaro e Mascaro (2009), demonstram que ambientes onde existem áreas verdes associadas com a arborização urbana contribuem para a melhoria da ambiência urbana de varias maneiras, principalmente relacionadas à diminuição do desconforto térmico. Segundo esses mesmo autores em recintos urbanos arborizados, as copas das árvores reduzem o fator de céu visível e, consequentemente, gera o resfriamento passivo do recinto.

Muitos projetistas e construtores têm desconsiderado os recursos que a natureza coloca à disposição, ignorando o fato de que tais recursos são capazes de colaborar de forma eficaz no conforto térmico ambiental.

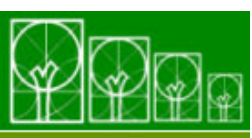

$\mathbf{S} \cdot \mathbf{B} \cdot \mathbf{A} \cdot \mathbf{U}$ Soc. Bras. de Arborização Urbana 
Georgi e Tzouri (2008) registraram as medidas de temperatura e umidade durante os meses de verão na cidade de Drama, na Grécia em dois pontos distintos: um deles no parque central da cidade, rico em vegetação e recursos hídricos e o outro numa praça com pouca vegetação e muitos edifícios. Concluíram que as condições microclimáticas foram muito mais favoráveis no parque central rico em vegetação e recursos hídricos por este apresentar temperatura $2^{\circ} \mathrm{C}$ inferior com relação à praça cercada por edifícios, cuja umidade relativa foi $4 \%$ superior.

Estudos realizados em locais de climas áridos como Marrakesh, na África e Phoenix-Arizona, na América do Norte, indicaram que a radiação solar influencia as atividades praticadas em ambientes ao ar livre, principalmente no verão. Ambientes com presença de vegetação permitem que pessoas gastem mais tempo realizando atividades que aqueles com ausência desta (ALJAWABRA; NIKOLOUPOULOU, 2009).

Segundo Nikolopoulou (2001), as condições de conforto térmico afetam o comportamento das pessoas e o uso dos espaços abertos. Estudos realizados por este mesmo autor em Atenas e Cambridge revelaram que os parâmetros microclimáticos influenciaram fortemente a sensação de conforto e por consequência o uso do espaço, de maneira que em dias de altas temperaturas, locais pouco arborizados e sem sombreamento são pouco utilizados afetando o desenvolvimento de cidades turísticas.

Dacanal et al. (2010) investigou o papel dos maciços florestais urbanos (bosques) no conforto térmico dos usuários. Os resultados microclimáticos confirmaram que o microclima dos locais é relativamente estável ao longo das estações, o que é positivo para a adaptação térmica humana. Os índices de conforto PMV (predicted mean vote) e PET (physiological equivalent temperature) confirmaram a prevalência do conforto térmico no interior dos bosques. A PET, mais apropriada para espaços abertos, mostrou boa correlação com os votos de conforto obtidos por meio de questionários, confirmando o intervalo proposto por Jendritzky et al. (1990) e calibrado por Monteiro e Alucci (2007) para São Paulo.

Segundo Baltar et al. (2006), o conforto térmico no ambiente também pode proporcionar economia de energia elétrica. Medidas de redução de consumo e aproveitamento racional dos recursos naturais ficam atualmente sob a responsabilidade dos projetistas, que pela indiferença ou até mesmo pelo desconhecimento de técnicas naturais de conforto não projetam edificações energicamente eficientes.

As soluções construtivas e os materiais utilizados na indústria da construção civil são responsáveis diretos pelo consumo de energia das edificações. Desta forma a

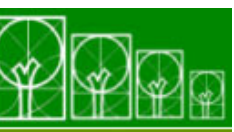

$\mathbf{S} \cdot \mathbf{B} \cdot \mathbf{A} \cdot \mathbf{U}$ Soc. Bras. de Arborização Urbana 
utilização correta dos recursos naturais possibilita a minimização dos gastos energéticos com sistemas de climatização. Nesse contexto, é de interesse da indústria da construção a discussão do uso de alternativas que utilizem recursos naturais de conforto térmico desde a concepção dos projetos até a construção.

Donovan e Butry (2009) observaram que as árvores quando devidamente posicionadas no entorno das casas, proporcionam economia de energia tanto para o consumidor final (US\$167,00 em 20 anos) quanto para as empresas fornecedoras (US\$ 63,00 em 20 anos).

Segundo Mascaró (2006), a principal função da arborização no meio ambiente urbano, principalmente no clima subtropical úmido, é de sombreamento. Quando a rua tem árvores de grande porte que se igualam com a altura dos edifícios, o sombreamento da vegetação é mais significativo, reduzindo a importância dos efeitos da geometria e da orientação do recinto urbano, diminuindo a assimetria das sombras decorrentes da orientação do eixo da rua. Devido ao baixo valor do albedo ${ }^{4}$, a energia que gasta nos processos fisiológicos e a quantidade de vapor de água que produz, a vegetação constitui o material ideal para ser utilizado como sombreamento de verão da cidade.

O programa de plantio de árvores representa uma rara oportunidade de melhorar a qualidade de vida simultaneamente do cidadão e do ambiente urbano através da diminuição dos custos de energia elétrica, principalmente nas regiões úmidas (McPherson; Simpson, 2003).

Entretanto, não há planos precisos e completos de plantio de árvores urbanas que levem em consideração a função ambiental da vegetação que estejam sendo aplicados entre nós. As ações realizadas estão mais voltadas para atender aqueles aspectos de embelezamento da área urbana (BOMMEL et al., 2006), que a dar resposta aos aspectos ambientais e energético do recinto urbano.

\section{CONCLUSÃO}

$\mathrm{Na}$ busca por uma cidade mais confortável, é necessário sensibilização dos planejadores urbanos para a incorporação dos conceitos discutidos nessa revisão.

\footnotetext{
${ }^{4}$ Nota sobre o que é albedo

Albedo é uma medida relativa da quantidade de luz refletida.
} 
É desejável que esses planejadores utilizem os resultados de pesquisas dos especialistas de diversas áreas do conhecimento, tais como meteorologistas, bioclimatologistas, biólogos, engenheiros, arquitetos e outros que se dedicam a construção de informações sobre conforto térmico em ambiente urbano.

Observa-se que o uso da vegetação como dispositivo de sombreamento, gerador de umidade e o recurso de ventilação natural são bastante eficientes como recursos de conforto térmico além de exigirem pouco financeiramente para sua implantação e manutenção.

Conhecendo os benefícios e possibilidades dos processos de ventilação natural assim como a implantação da vegetação das cidades, para conforto térmico humano, podemos concluir sob os aspectos abordados na revisão bibliográfica que é possível um ambiente naturalmente sombreado, refrigerado e ventilado ser totalmente eficiente para o conforto, contribuindo para a eficiência energética, desde que se compreendam as condicionais para o conforto e as leis de movimentação de ar, seus efeitos e suas possibilidades assim como as propriedades específicas de cada espécie vegetal (características de sombreamento e evapotranspiração), ainda pouco investigada pela comunidade científica.

\section{REFERÊNCIAS BIBLIOGRÁFICAS}

ABREU, L. V. Estudo do raio de influência da vegetação no microclima por diferentes espécies arbóreas. Dissertação (Mestrado em Engenharia Civil) - Faculdade de Engenharia Civil, Arquitetura e Urbanismo, Universidade Estadual de Campinas, 2008. $154 p$.

ALJAWABRA, F.; NIKOLOPOULOU, M. Outdoor Thermal Comfort in the Hot Arid Climate: the effect of socio-economic background and cultural differences. In: PLEA, 26th CONFERENCE ON PASSIVE AND LOW ENERGY ARCHITECTURE, 2009, Quebec City. Proceedings... Quebec City, Canada, June, 2009, 22 - 24.

ANDREASI, W. A. A Ventilação natural como estratégia visando proporcionar conforto térmico e eficiência energética no ambiente interno. UFMS, 2007. Disponível em: <http://www.dec.ufms.br/lade/docs/dt/rogerio.pdf>. Acesso em: 19 de mai. 2011.

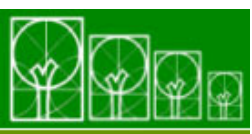

$\mathbf{S} \cdot \mathbf{B} \cdot \mathbf{A} \cdot \mathbf{U}$ Soc. Bras. de Arborização Urbana 
ASHRAE. AMERICAN SOCIETY OF HEATING, REFRIGERATING AND AIRCONDITIONING ENGINEERS (ASHRAE) 1992. ASHRAE Standard 55: Thermal Environmental Conditions for Human Occupancy, Atlanta, GA.: ASHRAE

BALTAR, M. G.; KAEHLER, J. W. M.; PEREIRA, L. A. Indústria da Construção Civil e Eficiência energética. PPGEE - Programa de Pós-Graduação em Engenharia Elétrica Pontifícia Universidade Católica do Rio Grande do Sul, Porto Alegre, RS, Brasil, 2006. Disponível em: <http://tede.pucrs.br/tde_arquivos/11/TDE-2006-11-16T200104Z123/Publico/384715_anexo_5.pdf>. Acesso em: 19 de out. 2010.

BOUTET, T. S. Controlling air movement. 2 ed. USA: RR Donnelley e Sons Company, 1987. $318 p$.

BROWN, G. Z.; DEKAY, M. Sun, Wind and Light: Architectural Design Strategies. Second edition. Hoboken, NJ: Wiley e Sons. November, 2000.

BUENO, C. L. A influência da vegetação no conforto térmico urbano no ambiente construído. Tese (Doutorado em Saneamento e Ambiente) - Faculdade de Engenharia Civil, Universidade Estadual de Campinas, 2003.

DACANAL, C.; LABAKI, L. C.; SILVA, T. M. L. Vamos passear na floresta! O conforto térmico em fragmentos florestais urbanos. Ambiente Construído, v. 10, n. 2, 2010.

DIMOUDI, A. NIKILOPOULOU, M.; Vegetation in the urban environment: Microclimatic analysis and benefits. Energy and Buildings, Inglaterra, v. 35, n. 1, p. 69-76, 2003. Disponível em: <http://www.elsevier.com/locate/enbuild> Acesso em: 16 de abr. 2010

DONOVAN, G. H.; BUTRY, D. T. The value of shade: estimating the effect of urban trees on summertime electricity use. Energy and Buildings, n.41, 2009. p.662-668.

FONTES, M. S. G. C; DELBIN S. Efeito climático de uma área verde no ambiente Urbano. In: IX ENCONTRO NACIONAL DE TECNOLOGIA DO AMBIENTE CONSTRUÍDO, Anais... ANTAC: Foz do Iguaçu, PR, 2002, p. 971-980. 
FURTADO, A. E. Simulação e Análise da Utilização da Vegetação como Anteparo às Radiações Solares em uma Edificação. Dissertação (Mestrado em Ciências da Arquitetura) - Faculdade de Arquitetura e Urbanismo da UFRJ, Rio de Janeiro, 1994.

GEORGI, J. N.; DIMITRIOU, D., The contribution of urban green spaces to the improvement of environment in cities: Case study of Chania, Greece, Building and Environment, Volume 45, Issue 6, June 2010, Pages 1401-1414. Disponível em: <http://www.sciencedirect.com/science/article/pii/S0360132309003564>. Acesso em: 19 de mai. 2011.

GEORGI, N.; TZOURI, A. Monitoring thermal comfort in outdoor urban spaces for bioclimatic conditions improvement. In: 1st WSEAS, International Conference on Landscape Architecture (LA'08), Algarve, Portugal, June 11-13, 2008.

GRATIA, E.; BRUYÈRE, I.; DE HERDE, A. How to use natural ventilation to cool narrow office buildings. Building and Environment n.39 p.1157 - 1170, 2004.

JONES, J.; WEST, A.W. Natural Ventilation and Collaborative Design. ASHRAE Journal. November, 2001.

JENDRITZKY G.; SCHIRMER H.; MENZ G.; SCHMIDT-KESSEN W. Methode zur raumbezogenen Bewertung der thermischen Komponente im Bioklima des Menschen (Fortgeschriebenes Klima-Michel-Modell). Beiträge Akad Raumforschung Landesplanung Hannover, v. 114, p. 7-69, 1990.

LABAKI, L. C. Conforto humano: aspectos arquitetônicos e urbanísticos. Campinas: Departamento de Arquitetura e Construção - Faculdade de Engenharia Civil, Arquitetura e Urbanismo, UNICAMP, $2011 . \quad$ Disponível em: $<$ http://www.sbbiomet.com.br/cms/index.php?option=com_content\&task=view\&id=59\&ltemid $=47 \& \mathrm{mnu}=$ sc5 $>$. Acesso em: 15 de mar. 2011.

LAMBERTS, R. et al., Building Bioclimatology in Brazil. In: The 14 th International Conference on Passive and Low Energy Architecture. PLEA 97, Kushiro, Japan. Proceedings... 1997. p. 203-208.

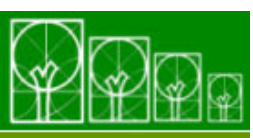

$\mathbf{S} \cdot \mathbf{B} \cdot \mathbf{A} \cdot \mathbf{U}$ Soc. Bras. de Arborização Urbana 
LEFF, H. Saber ambiental: sustentabilidade, racionalidade, complexidade, poder. Petrópolis: Vozes, 2001.

LECHNER, N.; Heating, cooling, lighting: design methods for architects. 2 ed. Canadá: John Willey \& Sons, 1990. 648 p.

LIMA, F. K. G. M.; ROMERO, M. A. B.; Espaços Residuais Públicos: um estudo morfológico e bioclimático em bairro de renda média-baixa em Teresina. In: ENCONTRO NACIONAL E LATINO-AMERICANO SOBRE CONFORTO NO AMBIENTE CONTRUÍDO, VII e IV, 2005, Maceió, AL. Anais... Maceió, AL: ANTAC, 2005. CD rom.

LLANDERT, L. R. A.; Zonas verdes y espacios libres en la ciudad. Madrid: Instituto de Estudios de Administración Local, 1982. 538 p.

LOMBARDO, M. A. Ilhas de calor nas metrópoles: o exemplo de São Paulo. São Paulo: Hucitec, 1985.

LOPES, P. M. O. Obtenção de regimes microclimáticos em regiões montanhosas com dados de sensores orbitais e integração de modelos distribuídos. Tese (Doutorado em Sensoriamento Remoto) - Instituto Nacional de Pesquisas Espaciais. São José dos Campos, 2006. 230 p.

MALLICK, F. H., Thermal comfort and building design in the tropical climates, Energy and Buildings, Volume 23, Issue 3, PLEA '94 International Conference, March 1996, p. 161-167, ISSN 0378-7788, DOI: 10.1016/0378-7788(95)00940-X. Disponível em: <http://www.sciencedirect.com/science/article/pii/037877889500940X>. Acesso 19 mai. 2010

MASCARÓ, J. J. Significado Ambiental - Energético da Arborização Urbana. Revista de Urbanismo e Arquitetura, Vol. 7, No 1, 2006.

MASCARÓ, L. Ambiência Urbana. 2. ed. Porto Alegre: +4 Editora, 2004.

MASCARÓ, L; MASCARÓ, J. Ambiência Urbana - Urban Environment, 3. Ed. Porto Alegre: Masquatro Editora, 2009, 200p.

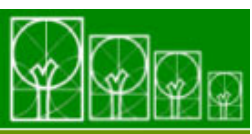

$\mathbf{S} \cdot \mathbf{B} \cdot \mathbf{A} \cdot \mathbf{U}$ Soc. Bras. de Arborização Urbana 
Vegetação Urbana. 2. ed. Porto Alegre: +4 Editora, 2005.

MCPHERSON, E. G.; SIMPSON, J. R. Potential energy savings in buildings by an urban tree planting program in California, Urban Forestry and Urban Greening 2 (2003), pp. 7386.

em:

$<$ http://www.sciencedirect.com/science?_ob=MiamilmageURL\&_imagekey=B7GJD4DPXHF3-W-

1\&_cdi=20204\&_user=5674931\&_pii=S1618866704700254\&_check=y\&_origin=\&_coverDat $\mathrm{e}=01 \% 2 \mathrm{~F} 01 \% 2 \mathrm{~F} 2003 \&$ view=c\&wchp=dGLbVzW-

zSkzS\&md5=cfe2e2c8cbf3f53f46676af7d4552e54\&ie=/sdarticle.pdf >. Acesso em: 16 de abr. 2011.

MELLO FILHO, L. E. Arborização urbana. In: Encontro Nacional sobre Arborização Urbana, I, 1985. Porto Alegre. Anais... Porto Alegre, 1985. p. 45-49.

MILANO, M. S. Planejamento e replanejamento de arborização de ruas. In: ENCONTRO NACIONAL SOBRE ARBORIZAÇÃO URBANA, Maringá. Anais... v.2, 1987. p. 1-8.

MONTEIRO, L. M.; ALUCCI, M. P. Conforto Térmico em Espaços Abertos com Diferentes Abrangências Microclimáticas: parte 2: proposição de calibração de modelos preditivos. In: ENCONTRO NACIONAL, 9., ENCONTRO LATINO AMERICANO DE CONFORTO NO AMBIENTE CONSTRUíDO, 5., 2007, Ouro Preto. Anais... Porto Alegre: ANTAC, 2007. p. 1231-1240.

NERY, J.; ANDRADE, T.; FREIRE, T.; KATZSCHNER, L. Thermal Comfort Studies in Humid Tropical City, Salvador- Brazil. In: ICUC- INTERNATIONAL CONFERENCE OF URBAN CLIMATE, VI., 2006, Goteborg, Sweden. Proceedings... Goteborg, Sweden: IAUC Newsletter, 2006. Disponível em: <http://www.urban-climate.org/lAUC018.pdf>. Acesso em: abr. 2010.

NIKOLOPOULOU, M. The effect of climate on the use of open spaces in the urban environment: relation to tourism. In: Workshop on Climate Tourism and Recreation, International Society of Biometeorology. North Chalkidiki, Greece, October 2001.

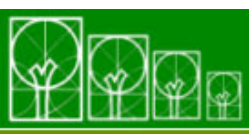


NOBILE, A. A.; Diretrizes para sustentabilidade ambiental em empreendimentos

habitacionais. Dissertação (Mestrado) - Faculdade de Engenharia Civil, Arquitetura e Urbanismo, Universidade Estadual de Campinas. Campinas, 2003. 386 p.

OKE, T. R. Boundary layer climates. London: Methuen, 1978. 372 p.

PAULA, R. Z. R. A influência da vegetação no conforto térmico do ambiente construído. Dissertação (Mestrado) - Faculdade de Engenharia Civil, Arquitetura e Urbanismo, Universidade Estadual de Campinas. Campinas, 2004. 100 p.

SCHIFFER, S. R.; FROTA, A. B., Manual de Conforto Térmico, 6.ed. São Paulo: Studio Nobel, 1999.

SCHIFFER, S. R.; FROTA, A. B., Manual de Conforto Térmico, 7.ed. São Paulo: Studio Nobel, 2003.

SHAMS, J. C. A; GIACOMELI, D. C; SUCOMINE, N. M. Emprego da Arborização na Melhoria do Conforto Térmico nos Espaços Livres Públicos. Piracicaba: Revista da Sociedade Brasileira de Arborização Urbana, v.4, n.4, p.1-16, 2009.

TERJUNG, W. H.; LOUIE, S. S. F.; A Climatic Model of Urban Energy Budgets. Geographic Analysis, v. 6, p. 341-367, 1974.

BOMMEL, F. P. J.; HEITK"ONIG, I. M. A.; EPEMA, G. F. ; RINGROSE, S.; BONYONGO, C.; VEENENDAAL, E. M., Remotely sensed habitat indicators for predicting distribution of impala (Aepyceros melampus) in the Okavango Delta, Botswana. Cambridge University Press. Journal of Tropical Ecology, v. 22, p.101-110, 2006.

YOCHIDA, A.; SUGIOKA, M. Development of three dimensional plant canopy model for numerical simulation of outdoor thermal environment. In: ICUC - INTERNATIONAL CONFERENCE ON URBAN CLIMATE, VI, 2006, Goteborg, Sweden. Proceedings... Goteborg, Sweden: IAUC Newsletter, 2006. 